\title{
COMPULSORY VOTING AND GOVERNMENT SPENDING
}

\author{
Trinity Economic Paper Series \\ Technical Paper No. 94/4 \\ JEL Classification D72 \& H30
}

\author{
Francis O'Toole \\ Department of Economics \\ Trinity College Dublin \\ Dublin 2
}

\author{
Eric Strobl \\ Department of Economics \\ Trinity College Dublin \\ Dublin 2
}

\begin{abstract}
$\underline{\text { Abstract }}$
In a recent issue of Economics and Politics Crain and Leonard (1993) described the effects of compulsory voting on government spending. The purpose of this paper is twofold. First, problems in Crain and Leonard's approach are identified. Their use of the median-voter model appears inconsistent and their choice of government consumption rather than government expenditure is questionable. Second, this paper begins an analysis of the composition of government expenditure. Cross-country data tentatively suggests that non-voters benefit relative to voters from government expenditure on health, housing and transfer payments while voters benefit from government expenditure on defense and economic services.
\end{abstract}

\section{INTRODUCTION}


In a recent issue of Economics and Politics Crain and Leonard (1993) address the issues of compulsory voting rules and voluntary voting rules. The authors approach this inquiry from the novel perspective of the effects of compulsory and voluntary voting rules on government fiscal policies and, in particular, on the scale of government expenditure. Two models are proposed by the authors to explain divergences in the scale of government expenditure across countries with different voting rules: the median-voter model, which in the context of the present topic, focuses attention on the demographic characteristics of voters, and the pressure group model which is based on the self-interested behaviour of lobby groups. ${ }^{1}$

The rationale for this paper is twofold. First, certain problems underlying Crain and Leonard's approach are identified. In particular, it is argued that the median-voter model is used in an inconsistent manner by the authors. More seriously, it is also argued that the choice of general government consumption rather than central government expenditure is inconsistent with the use of either model in the present context. General government consumption includes expenditure by noncentral government but excludes transfer payments.

Second, this paper attempts to build upon the insights offered by Crain and Leonard's approach. Rather than focusing upon the size of government expenditure this paper focuses upon the composition of government expenditure. The starting point for this analysis is the assumption that the pressure group model is the appropriate model for explaining differences in government expenditure policies pursued by countries with compulsory voting rules and countries with voluntary voting rules. Given the reasonable assumption that government expenditure policies pursued by countries with compulsory voting rules are more likely to incorporate the

\footnotetext{
${ }^{1}$ See Bardhan and Roemar (1992, p.104) for the use of these two approaches in an alternative context.
} 
preferences of people who would be voluntary non-voters under voluntary voting rules, the differences in government expenditure across countries with different voting rules allows us to infer the beneficiaries of the various components of government expenditure.

It should be noted that this paper does not attempt to address the more fundamental and complex issue of why people vote or do not vote under voluntary voting rules. One possible approach to this issue, consistent with the approach adopted in this paper, is to assume the existence of some exogenous voting cost which can differ in magnitude across individuals or groups. Under the pressure group model of expenditure determination voters are assumed to impose a negative fiscal spillover on non-voters, that is non-voters' taxes contribute towards government expenditure which is directed disproportionately towards voters. The absolute size of this fiscal spillover in the voluntary voting system is limited by the size of the exogenous voting cost confronting voluntary non-voters. If the fiscal spillover from voters to voluntary non-voters exceeded this exogenous cost then the voluntary non-voters would become voters.

Section 2 of this paper outlines the two alternative models proposed by Crain and Leonard to explain differences in government expenditure across countries utilizing compulsory voting and voluntary voting rules. Two sources of problems are identified in the model comparison procedure as carried out by the authors. The first issue concerns the rather ad-hoc identification of the net beneficiaries of government expenditure. The second, and more fundamental, issue concerns the choice of general government consumption rather than central government expenditure as the appropriate measure of the scale of "government". The authors' choice is particularly problematic in the context of the proposed explanation of the fiscal outcomes of the voting processes.

Section 3 attempts to build upon the strengths of Crain and Leonard's novel 
approach to analysing government expenditure. The focus of attention moves from the scale of government involvement in total expenditure in the economy to the composition of government expenditure. By accepting the pressure group approach to the determination of the composition of government expenditure differences in government expenditure patterns across counties with compulsory and voluntary voting rules are used to identify the net beneficiaries of various components of government expenditure.

Section 3 also outlines the results derived from this analysis. Although the econometric results cannot be regarded as definitive in terms of levels of statistical significance, it is clear that the composition of government expenditure is influenced by the choice of voting rule. In particular, under compulsory voting rules as opposed to voluntary voting rules, expenditure on defense and economic services is relatively lower while expenditure on health is relatively higher. Expenditure on housing, which also incorporates expenditure on transfer payments due to data limitation problems, is relatively higher under compulsory voting but not to a very significant extent. Expenditure on education displays no systematic relationship to voting rules but data limitations do not allow us to decompose education expenditure into expenditures on the different levels of education.

These results suggest that in a country with voluntary voting rules, non-voters tend to benefit (relative to voters) from government expenditure on health and, to a smaller extent, housing and transfer payments. In other words, government expenditure on health tends to be more redistributive towards the type of individual who is a non-voter while government expenditure on defence and economic services tends to be more redistributive towards the type of individual who is a voter.

The conclusion notes the contribution of this paper to the economics and politics literature and suggests some further directions for a research strategy initially suggested by Crain and Leonard's paper. 


\section{CRAIN AND LEONARD'S ANALYSIS}

By analysing the effects of compulsory voting rules on the fiscal policies of a cross section of democratically elected governments, Crain and Leonard attempt to choose between two alternative models of governmental decision-making. These models will be referred to as the median-voter model and the pressure group model throughout the following discussion.

The median-voter model contrasts the demographic characteristics of voters under the voluntary and compulsory voting regimes. Under compulsory voting rules the number of non-voters is insignificant while under voluntary voting rules, the number of non-voters can be quite large. ${ }^{2}$ Crain and Leonard argue that the demographic characteristics of voluntary non-voters suggest that they are net gainers of government's fiscal policies. Consequently it is argued that the introduction of compulsory voting would shift the position of the median voter and increase government spending, "The demography-based analysis implies compulsory voting will increase the size of government relative to voluntary voting rules." (Crain and Leonard, 1993, p.44).

The pressure group model takes a more sceptical view of the voting process and sees government's decisions, and in particular fiscal decisions, as being influenced by the lobbying activities of self-interested pressure groups. In this model under voluntary voting rules non-voters are net losers of government's fiscal policies. The introduction of compulsory voting would curtail fiscal spillovers from voters to non-voters and consequently decrease government spending, "Thus, the interest group framework suggests that CVRs (compulsory voting rules) will reduce

\footnotetext{
2 "Participation rates average better than 90 per cent of the eligible population in the compulsory voting rules countries; in voluntary voting countries, average participation is closer to 50 per cent." (Crain and Leonard, 1993 p.43).
} 
government activity and expenditure." (Crain and Leonard, 1993, p.45).

Crain and Leonard's subsequent analysis deals with model selection. Their view of the relative amount of government spending under voluntary and compulsory voting rules in the median-voter model is, however, seriously flawed both in its foundations and in its implementation. Their conclusion that compulsory voting increases government spending in the median-voter model depends on two separate factors.

(1) The empirical observation that voluntary non-voters tend to be different, in particular, "..., the set of eligible non-voters tends to be: poorer, less-well educated, younger, and disproportionately higher in minority groups than the set of voluntary voters." Crain \& Leonard (1993, p.44).

(2) The claim that non-voters are net beneficiaries of government fiscal policies, "In short, voluntary non-voters are plausibly net recipients of government services." Crain \& Leonard (1993, p.44).

With regard to (1), Mueller (1989) in an overview of the characteristics associated with non-voting individuals argues "... income is consistently, positively correlated with the probability of voting." (p.365) and "Years of education have proven to be positively and significantly related to voter turnout in virtually every study of voter participation." (p.365). Despite reservations based on the fact that most studies are US-based and on the potentially troublesome issue of multicollinearity between some of the explanatory variables, e.g., rich, welleducated, member of majority groups..., it seems clear that voters and non-voters are different and that the direction of this difference in terms of, say, income is not in contention. 
With regard to (2), however, it is by no means clear that members of the group comprising "poorer, less-well educated, younger, and disproportionately higher in minority groups" are net gainers of government policies. Restricting attention to government's fiscal policies (as Crain and Leonard do), perhaps the best supporting evidence for the above view would be in health expenditures. For example, Barr (1987) in the context of the British national health system argues that,

"The national health service..., despite some inequalities, is remarkably egalitarian." (p.419).

With respect to transfer payments, where a priori, one might expect significant levels of vertical redistribution, the evidence is not overwhelming. Barr (1989) argues that,

"The overall success of cash benefits in practice is also controversial." (p.418).

One should, however, note that the overall redistributive effect of the tax-andtransfer system tends to be underestimated owing to the failure of policy analysts to correctly identify the relevant counterfactual to be used in comparing the before taxand-transfer system with the after tax-and-transfer system. In particular, gross income given the existence of a tax-and-transfer system is not the correct counterfactual. $^{3}$

Governments' spending behaviour on education and housing casts particular doubts on Crain and Leonard's rather benevolent view of governments' fiscal policies,

\footnotetext{
${ }^{3}$ See Ringen (1987, Chapter 8) for an excellent review of this issue and other related issues.
} 
"The evidence suggests that middle-class children on average receive a disproportionate share of educational resources in terms of both quantity and quality; and that these differentials cannot be attributed solely to differences in tastes. In addition, the finance of university education is almost certainly regressive." Barr (1987, p.419).

"Housing is the one major area where the welfare state has performed badly, not through choosing controversial aims, but by adopting methods which are unlikely to achieve them. ... The distributional effects of the subsidies are also largely perverse: owner-occupiers (mainly in the higher socio-economic groups) benefit disproportionately; and the redistributive impact of rent control and subsidies to local authority housing, despite some shift towards income subsidies in the 1980s, retains an arbitrary element." Barr (1987, p.419).

Overall, the evidence in favour of (2) is at best mixed and depends crucially on which facet of government policy one focuses on. It is difficult, however, to accept Crain and Leonard's argument that the validity of the median-voter model as an explanation of government expenditure depends upon the existence of a positive relationship between countries with compulsory voting and countries with relatively higher levels of government expenditure. The median-voter model has no obvious predictions to make with respect to the relationship between different voting rules and the scale of government expenditures. In effect, the median-voter model acts as a strawman. The median-voter may, however, have predictions to make with respect to the composition of government expenditure. This issue will be addressed in the next section.

Crain and Leonard's second proposed model stems from pressure group theories of government expenditure. The existence of compulsory voting, it is 
argued, reduces the possibility for fiscal spillovers from voters to non-voters and consequently reduces pressure groups' incentive to spend resources on lobbying in the first place. In positing a negative relationship between government expenditure and the existence of compulsory voting, however, the authors appear to be "jumping-the-gun". Although the scope for fiscal spillovers is reduced with the introduction of compulsory voting and consequently one may expect less government expenditure on items of particular benefit to voters under a voluntary voting system, is it not reasonable to expect increased government expenditure on items of particular benefit to non-voters under a voluntary voting system? Notwithstanding this question, however, it appears from Table 1, which shows Crain and Leonard's results, that the growth rate in the size of government is significantly lower under countries with compulsory voting rules. ${ }^{4}$ Table 1 displays the OLS regression results with T-statistics in parentheses where the explanatory variable is average government growth rate and the explanatory variables are: average annual growth rate for gross domestic product (GRGDP); a dummy variable for the existence of compulsory voting rules (CVR); a dummy variable for the enforcement of compulsory voting rules (ENFORCE); literacy rates (LITERACY) and national income per person (LVSTD).

It is apparent from these results that a negative relationship exists between the existence of compulsory voting (enforced or otherwise) and annual government growth rates. However, the authors' choice of dependent variable is not central government expenditure, as would appear to be the obvious candidate, but general government consumption. This is not an trivial matter as the following definitions from the World Development Report (1989) make clear:

\footnotetext{
4 Although Crain and Leonard's discussion centres on the effects of alternative voting rules on the size of "government", their subsequent analysis focuses on the growth rate in the size of "government". See Section III for further discussion on this point.
} 
General government consumption: "General government consumption includes all current expenditures for purchases of goods and services by all levels of government." (p.235).

Central government expenditure: "Central government expenditure comprises the expenditure by all government offices, departments, establishments, and other bodies that are agencies or instruments of the central authority of a country." (p.237).

The Report proceed to outlines the effect of these differences,

"Total expenditure (as a percentage of GNP) is more narrowly defined than the measure of general government consumption (percentage of GDP) ..., because it excludes consumption expenditure by state and local governments. At the same time, central government expenditure is more broadly defined because it includes government's gross domestic investment and transfer payments." (p.237).

Table 2 shows the significant differences between these two definitions in terms of actual values for a range of countries. In particular, it should be noted that no systematic difference between the two measurements across countries can be expected. Countries with a significant level of transfer payments, for example, will show a higher level of central government expenditure relative to general government consumption. Conversely, countries with federal systems of governments will show a lower level of central government expenditure relative to general government consumption.

In terms of Crain and Leonard's choice of general government consumption rather than central government expenditure, it is clear that their failure to incorporate 
transfer payments under government spending will tend to underestimate the growth in spending on an item which one would expect to increase significantly as countries move from a voluntary voting system to a compulsory voting system. In short, it would be surprising if "government" increased under compulsory voting if one used general government consumption rather than central government expenditure as the definition of government.

In summary, it can be argued that Crain and Leonard's paper does not contain two alternative models and that their choice of dependant variable contributes significantly to the negative relationship shown to exist between the growth in the size of government and the existence of a compulsory voting system. A more fruitful line of inquiry suggested, but not implemented, in their approach is to focus on the composition of government expenditure rather than on the scale of government expenditure.

\section{THE COMPOSITION OF GOVERNMENT EXPENDITURE}

Adopting either the median voter model or the pressure group model of the political process it is clear that government expenditure, both in size and composition, will more accurately reflect the tastes of the entire eligible-to-vote population under compulsory voting rules. ${ }^{5}$ In contrast, under voluntary voting rules the composition of government spending is biased towards the preferences of the voting population. The introduction of compulsory voting can be expected to reduce the negative fiscal spillovers from voters to non-voters and consequently by comparing the composition of government expenditure across different voting regimes the net gainers from various components of government expenditure can be revealed.

\footnotetext{
${ }^{5}$ This does not imply that societal welfare, however defined, is necessarily higher under compulsory voting rules nor does it imply that non-voters become "better-off" under compulsory voting. See the comments on the costs of voting above.
} 
The comparison of the components of government expenditure across voting systems is by way of each component of government expenditure as a percentage of total government expenditures. For reasons unclear, Crain and Leonard's analysis focused on the rates of change of the independent variable and one dependent variable rather than on the actual values of these variable at a point in time. Their procedure would fail to identify countries with significantly different levels of government expenditure so long as the growth rates of government expenditure were equivalent. Their analysis also excluded high-income countries so as to obtain "a more homogeneous test group" which seems rather unnecessary given their inclusion of the explanatory variable representing national income per person (LVSTD).

Data limitation problems restrict the scope of the economic analysis to some extent. The World Development Report (various years) provides a rich data set but data requirements are rather demanding in the present context and consequently all regressions are based on an analysis of central government expenditure behaviour in a total of 41 countries with democratically elected governments; 15 countries with compulsory voting rules and 26 countries with voluntary voting rules (See Table A in the Appendix for details).

The independent variables which are based on the breakdown of central government expenditure data available from the World Development Reports are,

Defense: Defense expenditure as a percentage of central government expenditure,

Education: Education expenditure as a percentage of central government expenditure,

Health: Health expenditure as a percentage of central government expenditure, 
Housing and Transfers: Housing and community amenities and social security and welfare expenditure as a percentage of central government expenditure, and

Economic Services: Expenditure on regulation, regional development and trade promotion as a percentage of central government expenditure.

Interested readers are directed towards International Monetary Fund (1986) for more details on the exact definitions and scope of these variables. It should also be noted that the reliability of the data in terms of comparability is difficult to guarantee, "... Caution should therefore be exercised in using the data for crosscountry comparisons." (World Development Report 1989, p.237). The following explanatory variables were utilized in the regressions,

CVR: A dummy variable signalling the existence of compulsory voting rules, ENFORCE: A dummy variable signalling the enforcement of compulsory voting rules, and

GNP/POP: Gross national product per person.

The last variable is incorporated into the regression analysis so as to account for changes in the proportional amount of expenditure on certain components of government expenditure as gross national product per capita increases. One would expect this variable to have positive effects on the absolute values of each component of central government expenditure but in terms of the proportion of government expenditure assigned to each category, matters are less predictable.

With respect to the two dummy variables, CVR and ENFORCE, the sign of the coefficients will allow us to infer some details on the net beneficiaries of government expenditure. If the proportion of central government expenditure on, 
say, defense is significantly lower under compulsory voting, i.e., a negative coefficient on the dummy variable representing compulsory voting (CVR), then defense expenditure can be assumed to disproportionately benefit the type of person who votes under a non-compulsory voting regime. Similar arguments hold for the other dependent variables: education; health; housing and community amenities and social security and welfare.

Table 3 shows the results of the OLS regressions for the relevant components of central government expenditure for the year 1991 where P-values or the observed levels of significance are given in parentheses. ${ }^{6}$ Table 3 only incorporates the dummy variable representing the existence of compulsory rules (CVR) but Table B in the Appendix shows that replacing CVR with the dummy variable ENFORCE which signals the enforcement, rather than the simple existence, of compulsory voting has only minor effects on the results.

In terms of the effects of voting rules on fiscal policies, Table 3 tentatively suggests that the adoption of compulsory voting rules decreases the proportional amount of government expenditure on defense and economic services. It also suggests that proportional expenditure on health and, to a smaller extent, housing and transfers increases under compulsory voting. Consequently it can be argued that if the pressure group model of policy formulation is appropriate, defense and economic services expenditures by a central government are of relative benefit to the type of individual who votes in a country with voluntary voting rules. Conversely, it may be argued that central government expenditure on health is of relative benefit to the type of person who does not vote in a country with voluntary voting rules. Given the pecuniary characteristics of voters and non-voters the above results tentatively suggest that central government expenditure on health and

\footnotetext{
${ }^{6}$ The smaller the P-value, the greater the evidence against the implicit assumption that the relevant co-efficient is zero.
} 
housing and transfers tends to be more egalitarian than central government expenditure on defense and economic services.

Although a direct comparison of Crain and Leonard's results with the present results is not possible for the many reasons outlined in the previous section, an insight into the difficulties underlying their approach can be gleaned from Table 4. The dependent variables in Table 4 represent the proportion of gross domestic product accounted for by general government consumption (G/GDP) and the proportion of gross national product accounted for by central government expenditures (GEXP/GNP). As the OLS regressions reveal the scale of government, when government is defined in terms of general government consumption rather than central government expenditures, is effected to a greater extent in terms of level of significance by the presence of compulsory voting rules. This is consistent with Crain and Leonard's approach.

\section{CONCLUSION}

This paper offers a positive analysis of alternative voting rules to the extent that it comments upon the different government expenditure patterns observed across countries with different voting rules. This paper avoids a more inclusive and normative analysis of the issues underlying the choice between compulsory and voluntary voting rules which would incorporate an analysis of the extra costs of voting imposed on voluntary non-voters under compulsory voting. The more philosophical issue of whether individuals should have the right not to vote not just the right to spoil their vote is also not addressed in the present paper.

This paper, however, makes a contribution to the growing literature in economics and politics. By focusing on the composition of government expenditure and by adopting the insights offered by pressure group theories of policy formation 
it is possible to identify the net beneficiaries of various components of government policies. Previous attempts to identify the net gainers and losers of particular government polices encountered numerous objections stemming from general equilibrium considerations. The approach outlined in this paper allows the data to tell us its own story.

Table 1: OLS Results on Annual Government Growth Rates: Average For 1980-1987 


\begin{tabular}{lllll}
\hline Variable & Model 1 & Model 2 & Model 3 & Model 4 \\
\hline INTERCEPT & -1.07 & 0.58 & -1.52 & 0.36 \\
& $(-0.74)$ & $(0.56)$ & $(-1.01)$ & $(0.34)$ \\
GRGDP & 0.50 & 0.60 & 0.55 & 0.65 \\
& $(2.10)$ & $(2.53)$ & $(2.25)$ & $(2.67)$ \\
CVR & -3.64 & -3.01 & & \\
ENFORCE & $(-2.78)$ & $(-2.41)$ & & \\
& & & -4.52 & -3.27 \\
LITERACY & & & $(-3.11)$ & $(-2.67)$ \\
& $(2.05$ & & 0.06 & \\
LVSTD & & 0.0011 & $(2.36)$ & \\
& & $(1.73)$ & & 0.0012 \\
\end{tabular}

Source: Table 2, Crain and Leonard (1993, p.47).

Table 2: General Government Consumption and Central Government Expenditure 1987

\begin{tabular}{lcc}
\hline & $\begin{array}{c}\text { General Government } \\
\text { Consumption } \\
\text { (\% of GDP) }\end{array}$ & $\begin{array}{c}\text { Central Government } \\
\text { Expenditure } \\
(\% \text { of GNP })\end{array}$ \\
\hline United States & 21 & 23.3 \\
Norway & 21 & 40.6 \\
Japan & 10 & 17.4 \\
Sweden & 27 & 42.9 \\
Canada & 20 & 24.2 \\
Denmark & 25 & 39.8 \\
Finland & 21 & 31.9 \\
\hline
\end{tabular}

Source: World Development Report 1989.

Table 3: OLS Results on Components of Government Expenditure 1991

Dependent Variables 


\begin{tabular}{llllll}
\hline \multicolumn{5}{c}{} & \multicolumn{5}{c}{ (as percentage of central government expenditure) } \\
& Defense & Education & Health & $\begin{array}{l}\text { Housing \& } \\
\text { Transfers }\end{array}$ & $\begin{array}{l}\text { Economic } \\
\text { Services }\end{array}$ \\
\cline { 2 - 6 } $\begin{array}{l}\text { Independent } \\
\text { Variables }\end{array}$ & & & & \\
INTERCEPT & 13.12 & 13.74 & 5.80 & 9.07 & 21.76 \\
& $(.00)$ & $(.00)$ & $(.00)$ & $(.00)$ & $(.00)$ \\
CVR & -3.60 & 0.48 & 3.33 & 4.89 & -5.92 \\
& $(.11)$ & $(.81)$ & $(.12)$ & $(.23)$ & $(.05)$ \\
GNP/POP & -.00017 & -.00027 & .00017 & .00138 & -.0005 \\
& $(.16)$ & $(.02)$ & $(.15)$ & $(.00)$ & $(.00)$ \\
\hline \hline
\end{tabular}

Table 4: Scale of Government 1991

\begin{tabular}{lllll}
\hline & \multicolumn{3}{c}{ Independent Variables } \\
& INTERCEPT & CVR & ENFORCE & GNP/POP \\
\hline Dependent Variables & & & \\
& 13.03 & -2.58 & .00036 \\
G/GDP & $(.00)$ & $(.15)$ & & $(.00)$ \\
& 12.28 & & & .0004 \\
& $(.00)$ & & -1.34 & $(.00)$ \\
& 23.86 & -2.62 & & .0006 \\
GEXP/GNP & $(.00)$ & $(.50)$ & & $(.00)$ \\
& 22.78 & & & \\
& $(.00)$ & & -0.06 & .0007 \\
& & & $(.88)$ & $(.00)$ \\
\hline
\end{tabular}

\section{Appendix}

Table A: Data 


\begin{tabular}{|c|c|c|c|c|c|c|c|c|c|c|}
\hline & CVR & ENF & DEF & EDUC & HLTH & HSE & SER & GNP/POP & G/GDP & GEX/GNP \\
\hline Argentina & 1 & 1 & 10 & 10 & 3 & 39 & 16 & 2790 & 4 & 13 \\
\hline Australia & 1 & 1 & 9 & 7 & 13 & 31 & 8.3 & 17050 & 19 & 28 \\
\hline Austria & 1 & 1 & 2 & 9 & 13 & 48 & 9.1 & 20140 & 18 & 40 \\
\hline Bolivia & 1 & 1 & 13 & 19 & 3 & 19 & 16.9 & 650 & 15 & 19 \\
\hline Brazil & 1 & 1 & 4 & 3 & 7 & 26 & 3.2 & 2940 & 9 & 35 \\
\hline Costa Rica & 1 & 1 & 0 & 19 & 32 & 13 & 8.6 & 1850 & 16 & 26 \\
\hline Domin. Rep. & 1 & 1 & 5 & 10 & 14 & 20 & 36.5 & 940 & 9 & 12 \\
\hline Ecuador & 1 & 1 & 13 & 18 & 11 & 3 & 11.8 & 1000 & 8 & 16 \\
\hline Greece & 1 & 1 & 7 & 6 & 9 & 1 & 8.8 & 6340 & 20 & 60 \\
\hline Guatemala & 1 & 0 & 13 & 20 & 10 & 8 & 21.7 & 930 & 6 & 12 \\
\hline Mexico & 1 & 0 & 2 & 14 & 2 & 13 & 13.4 & 3030 & 8 & 18 \\
\hline Panama & 1 & 1 & 5 & 17 & 21 & 24 & 6.1 & 2130 & 21 & 30 \\
\hline Paraguay & 1 & 1 & 13 & 13 & 4 & 15 & 12.8 & 1270 & 8 & 9 \\
\hline Singapore & 1 & 1 & 24 & 20 & 5 & 8 & 16.8 & 14210 & 11 & 22 \\
\hline Uruguay & 1 & 1 & 9 & 7 & 5 & 50 & 8.7 & 2840 & 13 & 27 \\
\hline Bangladesh & 0 & 0 & 10 & 11 & 5 & 8 & 34.4 & 220 & 11 & 15 \\
\hline Botswana & 0 & 0 & 13 & 21 & 5 & 16 & 16.8 & 2530 & 28 & 42 \\
\hline Canada & 0 & 0 & 7 & 3 & 5 & 36 & 11.2 & 20440 & 21 & 24 \\
\hline Denmark & 0 & 0 & 5 & 10 & 1 & 40 & 7.6 & 23700 & 25 & 42 \\
\hline Finland & 0 & 0 & 5 & 15 & 11 & 37 & 18.8 & 23980 & 24 & 31 \\
\hline France & 0 & 0 & 6 & 7 & 15 & 46 & 5.1 & 20380 & 18 & 44 \\
\hline Germany & 0 & 0 & 8 & 1 & 18 & 49 & 8.7 & 23650 & 18 & 33 \\
\hline India & 0 & 0 & 17 & 3 & 2 & 7 & 20.8 & 330 & 12 & 18 \\
\hline Ireland & 0 & 0 & 3 & 12 & 13 & 29 & 12.8 & 11120 & 16 & 48 \\
\hline Israel & 0 & 0 & 22 & 0 & 4 & 31 & 10.1 & 11950 & 28 & 36 \\
\hline S.Korea & 0 & 0 & 22 & 16 & 2 & 11 & 19.2 & 6330 & 11 & 17 \\
\hline Madagascar & 0 & 0 & 8 & 17 & 7 & 2 & 35.9 & 210 & 9 & 16 \\
\hline Nepal & 0 & 0 & 6 & 11 & 5 & 7 & 43 & 180 & 10 & 18 \\
\hline Netherlands & 0 & 0 & 5 & 11 & 12 & 43 & 6.4 & 18780 & 14 & 53 \\
\hline New Zealand & 0 & 0 & 4 & 12 & 12 & 37 & 10.6 & 12350 & 17 & 44 \\
\hline Norway & 0 & 0 & 8 & 9 & 10 & 39 & 17.5 & 24220 & 21 & 46 \\
\hline Pakistan & 0 & 0 & 28 & 2 & 1 & 3 & 11.6 & 400 & 13 & 22 \\
\hline Peru & 0 & 0 & 16 & 21 & 6 & 1 & 0 & 1070 & 5 & 9 \\
\hline Spain & 0 & 0 & 5 & 6 & 14 & 38 & 11 & 12450 & 16 & 34 \\
\hline Sri Lanka & 0 & 0 & 9 & 8 & 5 & 18 & 24.6 & 500 & 10 & 29 \\
\hline Sweden & 0 & 0 & 6 & 10 & 1 & 56 & 8 & 25110 & 27 & 44 \\
\hline Thailand & 0 & 0 & 17 & 20 & 7 & 6 & 24.3 & 1570 & 10 & 16 \\
\hline Turkey & 0 & 0 & 10 & 18 & 3 & 3 & 25.2 & 1780 & 17 & 30 \\
\hline UK & 0 & 0 & 11 & 3 & 13 & 32 & 8.5 & 16550 & 21 & 28 \\
\hline US & 0 & 0 & 22 & 2 & 14 & 29 & 10.1 & 22240 & 18 & 25 \\
\hline Zimbabwe & 0 & 0 & 17 & 23 & 8 & 4 & 22.4 & 650 & 21 & 36 \\
\hline
\end{tabular}

Table B: OLS Results on Components of Government Expenditure 1991

Dependent Variables

(as percentage of central government expenditure) 


\begin{tabular}{llllll} 
& Defense & Education & Health & $\begin{array}{l}\text { Housing \& } \\
\text { Transfers }\end{array}$ & $\begin{array}{l}\text { Economic } \\
\text { Services }\end{array}$ \\
\hline $\begin{array}{llllll}\text { Independent } \\
\text { Variables }\end{array}$ & & & & & \\
INTERCEPT & 12.53 & 14.11 & 5.86 & 9.05 & 21.29 \\
& $(.00)$ & $(.00)$ & $(.00)$ & $(.01)$ & $(.00)$ \\
ENFORCE & -2.94 & -0.28 & 3.86 & 5.92 & -6.0 \\
& $(.20)$ & $(.89)$ & $(.08)$ & $(.15)$ & $(.05)$ \\
GNP/POP & -.00015 & -.00028 & .00014 & .001 & -.00048 \\
& $(.21)$ & $(.01)$ & $(.15)$ & $(.00)$ & $(.00)$ \\
\hline \hline
\end{tabular}

\section{REFERENCES}

Bardhan,P. and J.E.Roemar, 1992, Market Socialism: A Case for Rejuvenation, 
Journal of Economic Perspective, 6, 101-116.

Barr,N., 1987, The Economics of the Welfare State (Weidenfeld and Nicolson: London).

Central Intelligence Agency, The W orld Factbook 1989.

Crain,W.M. and M.L.Leonard, 1993, The Right Versus The Obligation To Vote:

Effects On Cross-Country Government Growth, Economics and Politics, 5, 43-51.

Delury, George E., 1987, World Encyclopedia of Political Systems \& Parties, Volumes I and II.

International Monetary Fund, 1986, M anual on Government Finance Statistics.

Mueller,D.C., 1989, Public choicell (Cambridge University Press).

Ringen,S., 1987, The Possibility of Politics: A study in the political economy of the welfare state (Clarendon Press Oxford).

World Bank, W orld D evelopment Report (various years) (Oxford University Press). 